\title{
ENRAIZAMENTO DE ESTACAS CAULINARES DE KIWI (Actinidia chinensis PLANCH CV ABBOTT) TRATADAS COM AUXINAS E BORO
}

\author{
E.O. ONO1; J.D. RODRIGUES ${ }^{1}$; S.Z. DE PINHO 2 \\ 1 Depto. de Botânica-1B/UNESP, CEP: 18.618-000, Botucatu, SP \\ 2 Depto. de Bioestattstica-IB/UNESP, CEP: 18.618-000, Botucatu, SP
}

\begin{abstract}
RESUMO: O trabalho teve como finalidade, estudar o efeito de várias auxinas sintéticas em formulações comerciais e do boro, sobre o enraizamento de estacas caulinares de kiwi (Actinidia chinensis Planch. cv Abbott.). As estacas utilizadas continham dois nós e duas folhas cortadas ao meio, com aproximadamente $10 \mathrm{~cm}$ de comprimento, onde o corte basal em bisel foi realizado logo abaixo de um nó e 0 apical acima do outro no. $O$ efeito das auxinas, sobre o enraizamento de estacas caulinares de kiwi foi verificado mediante os seguintes tratamentos, aplicados sobre as bases das estacas: T1 (H2O); T2 (NAA 300 ppm); T3 (IBA 300 ppm); T4 (NAA 300 ppm + B); T5 (IBA 300 ppm + B); T6 (NAA 0,5\%-p6) e T7 (IBA 0,5\%-p06). Após o tratamento das estacas, estas foram plantadas em bandejas de enraizamento, contendo vermiculita pura e colocadas em câmara de nebulização, onde permaneceram por 120 dias, até a sua coleta. Para a avaliação do efeito de auxinas e do ácido bórico, sobre o enraizamento de estacas caulinares de kiwi, foram realizadas as seguintes observaçōes: 1. porcentagem de estacas enraizadas; 2 . análise de açúcares redutores e açúcares totais (em $\mathrm{g} / 100 \mathrm{~g}$ de matéria seca); 3 . análise de triptofano (em $\mu \mathrm{g} / 100 \mathrm{mg} \mathrm{de}$ matéria seca). Os resultados obtidos no processo de enraizamento de estacas caulinares de kiwi (Actinidia chinensis Planch.) variedade Abbott, levou a concluir que o inverno e outono foram as melhores épocas de coleta dos ramos de auxinas para a confeç̧̃a das estacas. 0 processo de enraizamento foi ainda incrementado com a aplicação exogena na base das estacas, sendo que 0 alto teor de açúcares redutores e totais beneficiou a maior porcentagem de enraizamento.
\end{abstract}

Descritores: Actinidia chinensis, NAA, IBA, boro, enraizamento, estacas

\section{ROOTING OF KIWI STEM CUTTINGS (Actinidia chinensis PLANCH. CV ABBOTT) TREATED WITH AUXINS AND BORON}

SUMMARY: This study was carried out to evaluate the effects of some synthetical auxins and bornn trade formulations in the rooting of stem cuttings of some kiwi (Actinidia chinensis Planch) varieties. The experiment was carried out in a misty nebulization chamber in the Botany Department, Bioscience Institute, UNESP, Botucatu SP. The stem cuttings had two nodes and two leaves cut in half, the basal cut was performed nearly a node and the apical one in the next upper node. The auxin effect in Actinidia chinensis Planch rooting stems was observed through seven different treatments: T1 $\left(\mathrm{H}_{2} \mathrm{O}\right)$; T2 (NAA 300 ppm); T3 (IBA 300 ppm); T4 (NAA 300 ppm + B); T5 (IBA $300 \mathrm{ppm}+$ B); T6 (NAA 0,5\%-talc) and T7 (IBA 0,5\%-talc), applied to the stem bases. After these treatments, the stems were placed in suitable rooting dishes, with pure vermiculite in a misty nebulization chamber for 120 days until collection. The evaluation of auxin and boric acid effects in kiwi stem cuttings was made based on the following observations: 1 . the percentage of rooted stem cuttings; 2 , reductor sugar and total sugar analyses (in $\mathrm{g} / 100 \mathrm{~g}$ of dry matter); and 3. tryptophan analyses (in $\mu \mathrm{g} / \mathbf{1 0 0} \mathrm{mg}$ of dry matter). The results showed that the winter and autumn seasons are the best for rooting of Actinidia chinensis Planch. stem cuttings. The use of auxins in the cuttings showed positive results too and the higher contents of reductor and total sugars, increased rooting percentage.

Key Words: Actinidia chinensis, NAA, IBA, cuttings, rooting, boron

\section{INTRODUÇÃO}

Segundo BOSMAN e UYS (1978), a multiplicação do kiwi pode-se dar através da propagação sexual por sementes e da propagação vegetativa, utilizando-se segmentos caulinares e radiculares para a formação de uma nova planta. Segundo os mesmos autores, a propagação por estacas caulinares é o método mais empregado na multiplicação dessa espécie. 
Apesar das estacas de raízes de kiwi darem bons resultados na propagação dessa planta, elas têm sido menos empregadas do que estacas de caules (STOUTEMYER, 1968; DONOVAN, 1976).

$\mathrm{Na}$ multiplicação através de estacas lenhosas, têm-se obtido baixa porcentagem de enraizamento. Já, na propagação por estacas caulinares semi-lenhosas, pode-se obter ate $90 \%$ de enraizamento, sendo portanto, o método mais empregado para uma rápida multiplicação dessa frutífera (BOSMAN e UYS, 1978).

Segundo POVES (1982) a reprodução por sementes apresenta como inconveniente, a falta de uniformidade dos porta-enxertos, devido à fecundação cruzada que ocorre entre as plantas. Portanto, a multiplicação por estacas, $́$ a forma usual de obtenção dos porta-enxertos dessa espécie, sendo necessário o emprego de técnicas adequadas e aplicação de reguladores vegetais, principalmente as auxinas sintéticas, existentes no mercado, para alcançar sucesso no processo de enraizamento dos segmentos caulinares.

HARTMANN et al. (1990) relatam que o emprego de auxinas se faz útil, para estimular e acelerar o enraizamento das estacas, uniformizando e induzindo a formação de raízes.

LEWIS (1980) enfatiza um relacionamento metab́lico no qual o boro, compostos fenólicos e peroxidases/IAA-oxidases interagem sobre cada um e com as auxinas. A relação entre boro, auxina e a atividade da peroxidase/IAA-oxidase não está claro, existindo opiniōes contraditórias. Por exemplo, a atividade da peroxidase é aumentada pela falta de boro em muitos tecidos (ODHNOFF, 1957), mas tem sua atividade diminuída em outros tecidos (DUTTA \& Mc ILRATH, 1964). Além disso, a atividade da IAA-oxidase pode ser aumentada pelo bom (PARISH, 1968).

Assim, os dados obtidos por JARVIS et al. (1983), em estacas de Phaseolus aureus Roxb., podem ser interpretadas em termos do boro, direta ou indiretamente, aumentar a oxidação do IAA, portanto, diminuindo os níveis de auxinas efetivas. Dessa forma, controla as concentrações eficientes de auxinas no sítio de iniciação de raízes, permitindo o desenvolvimento e o crescimento destas. Vários autores, afirmam que as raízes em estacas caulinares de plantas são iniciadas pela auxina, requerendo o seu crescimento ou sendo este, extremamente incrementado pelo boro (HEMBERG, 1951; WEISER, 1959; MIDDLETON et al., 1978).
Como a produção de kiwi no Brasil ainda é limitada, o custo do fruto é altíssimo, sendo o consumo restrito à apenas uma classe da população. Para tanto, há necessidade do aumento de áreas produtoras dessa espécie através dc aumento da produção de frutos $e$, consequentemente, diminuição do preço dos mesmos.

Portanto, o objetivo do presente trabalho foi verificar o efeito de várias auxinas sintéticas em formulações comerciais, as quais são de fácil acesso aos agricultores, no processo de enraizamento de estacas caulinares de kiwi para posterior produção de mudas.

\section{MATERIAL E MÉTODOS}

O presente experimento foi conduzido em câmara de nebulização localizada no Departamento de Botânica, do Instituto de Biociências, do Campus de Botucatu - UNESP.

Foram utilizadas estacas de ramos semilenhosos de kiwi (Actinidia chinensis Planch.) variedade Abbott, contendo dois nós e duas folhas cortadas ao meio, com aproximadamente $10 \mathrm{~cm}$ de comprimento, conforme recomendado por ZUCCHERELLI E ZUCCHERELLI (1980).

$O$ efeito das auxinas, sobre o enraizamento de estacas caulinares de kiwi, foi verificado mediante o tratamento das mesmas com as seguintes substâncias (WEAVER, 1982):

- ácido indol-butírico (IBA - utilizado na forma do produto comercial Q-Muda, em talco, contendo ácido indol-butírico a $0,5 \%$, fabricado pela Microbiológica);

- ácido naftaleno-acético (NAA - utilizado na forma do produto comercial NAFUSAKU, em talco, contendo ácido naftaleno-acético a 0,5\%, embalado pelo Laboratório OKOCHI Ltda);

- NAA (utilizado na forma do produto comercial NAFUSAKU, produto contendo ácido naftalenoacético a $20 \%$, embalado pelo Laboratório OKOCHI Ltda., na concentração de 300 ppm de NAA);

- IBA (produto P.A., sintetizado pela Microbiológica, na concentração de 300 ppm);

- Ácido bórico P.A., na concentração de $150 \mu \mathrm{g} /$ ml 
Aproximadamente $1 \mathrm{~cm}$ da base das estacas foram mergulhadas no IBA e NAA na forma de talco (HARTMANN et al., 1990). Nos tratamentos contendo auxinas sintéticas mais boro, o último foi dissolvido na própria solução de NAA ou IBA. Em seguida, $2,5 \mathrm{~cm}$ da base das estacas foram imersas nessas soluções por, aproximadamente, 24 horas.

Das combinações entre auxinas e ácido bórico, foram realizados os seguintes tratamentos, aos quais as estacas de kiwi foram submetidas: T1 ( $\mathrm{H}_{2} \mathrm{O}$ ); T2 (NAA $300 \mathrm{ppm}$ ); T3 (IBA $300 \mathrm{ppm}$ ); T4 (NAA 300 ppm + B); T5 (IBA 300 ppm + B); T6 (NAA 0,5\%-p6) e T7 (IBA 0,5\%-p6).

Após o tratamento estas foram plantadas em bandejas de enraizamento, contendo vermiculita pura e colocadas na câmara de nebulização, onde permaneceram por 120 dias, até a sua coleta (POVES, 1982).

Para a avaliação do efeito de auxinas e do ácido bórico, sobre o enraizamento de estacas caulinares de kiwi foram realizadas as seguintes observações: a. porcentagem de estacas enraizadas; b. análise de açúcares redutores e açúcares totais (em $\mathrm{g} / 100 \mathrm{~g}$ de matéria seca) e c. análise de triptofano (em $\mu \mathrm{g} / 100 \mathrm{mg}$ de matéria seca).

Além disso, foram verificados o efeito dos 7 tratamentos em quatro épocas diferentes, que corresponderam às estações do ano (primavera, verão, outono e inverno). Esse procedimento foi realizado no intuito de averiguar a melhor época de coleta dos ramos de kiwi para a confecção das estacas, visando maior êxito de enraizamento.

Para a análise de açúcares redutores, açúcares totais e triptofano, segmentos caulinares de kiwi foram secados em estufa de circulação forçada de ar, à $60-70^{\circ} \mathrm{C}$. Após a secagem, o material vegetativo foi moído $\mathrm{em}$ moinho do tipo
Wiley, com peneira de malha 20 mesh. A análise foi também realizada em amostras de estacas, anteriormente aos tratamentos auxínicos e após a coleta das estacas.

A determinação de açúcares redutores e açúcares totais foi realizada através do método de Somogy-Nelson (NELSON, 1944), para amostras secas, e o método utilizado para a determinação de triptofano foi o realizado no Laboratório de Bioquímica de Plantas do CENA/USP, baseado no método da nihidrina (KERSTEN, 1990).

$O$ delineamento experimental utilizado foi o inteiramente casualizado com 7 tratamentos em cada Época, com 2 repetições. Cada parcela foi . constituída de, em média, 16 estacas, variando em função da disponibilidade de material vegetativo. Os parâmetros estudados foram submetidos à análise de variância (teste F) em cada Época c, posteriormente, reunidos em uma análise conjunta, segundo PIMENTEL GOMES (1990). Os dados de porcentagem de estacas enraizadas foram transformados em arc sen $(x \sqrt{100})$.

Os resultados para porcentagem de estacas enraizadas, não serão apresentados através da análise estatística, devido a grande variabilidade e valores nulos ocorridos. Portanto, os resultados serão discutidos, somente pelas médias das repetições.

\section{RESULTADOS}

Porcentagem de estacas enraizadas: Os resultados obtidos para porcentagem de enraizamento de estacas de kiwi (Actinidia chinensis Planch.), estão apresentados na Tabela1. Na primavera, as estacas tratadas com NAA $300 \mathrm{ppm}$ (T2) e IBA

TABELA 1. Dados médios de porcentagem de enraizamento de estacas caulinares de kiwi (Actinidia chinensis Pl.) var. Abbott, de ramos coletados nas 4 épocas de estudo.

\begin{tabular}{lcccc}
\hline \hline & \multicolumn{4}{c}{ Epocas } \\
\cline { 2 - 5 } Tratamentos & Primavera & Verão & Outono & Inverno \\
T1 - H2O & 12,5 & 11,1 & 22,5 & 35,8 \\
T2 - NAA 300ppm & 15,0 & 27,8 & 7,5 & 0 \\
T3 - IBA 300ppm & 15,0 & 5,6 & 15,0 & 7,2 \\
T4 - NAA 300ppm + B & 12,5 & 33,3 & 30,0 & 21,5 \\
T5 - IBA 300ppm + B & 0 & 22,2 & 15,0 & 14,3 \\
T6 - NAA 0,5\%-pó & 2,5 & 5,6 & 37,5 & 71,4 \\
T7 - IBA 0,5\%-p6 & 2,5 & 0 & 22,5 & 35,8 \\
\hline
\end{tabular}


$300 \mathrm{ppm}$ (T3), apresentaram valores médios maiores de porcentagem de enraizamento em relação aos demais tratamentos, enquanto que os tratamentos com IBA $300 \mathrm{ppm}+$ B (T5), NAA 0,5\% (T6) e IBA 0,5\% (T7), apresentaram os menores valores. Além disso, pode-se observar que a adição de boro não incrementou a porcentagem de enraizamento.

Para estacas de ramos coletados no verão o tratamento T4 (NAA $300 \mathrm{ppm}+\mathrm{B}$ ), foi aquele que exibiu a maior porcentagem de estacas enraizadas e o tratamento T7 (IBA 0,5\%) a menor. Pode-se notar ainda que, a adição de boro tanto com NAA ou IBA foi benéfica, aumentando a porcentagem de estacas enraizadas.

Estacas de ramos coletados no inverno e outono tenderam a apresentar os melhores resultados, sendo o tratamento T6 (NAA 0,5\%) o mais promissor. Nesta epoca também, pode-se observar que tratamentos auxínicos com a adição de boro aumentou a porcentagem de enraizamento.

Teor de açúcares redutores : Os resultados obtidos para conteúdo de açúcares redutores nas estacas de kiwi 'Abbott', antes e aposs os tratamentos estâo apresentados na Figura 1.

Através da Figura 1, pode-se verificar que, anteriormente aos tratamentos auxínicos (controle),

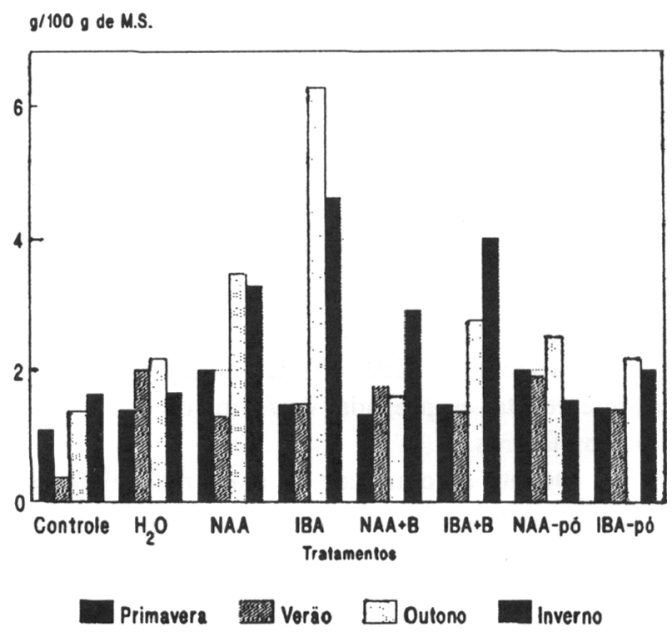

Figura 1. Conteúdo de açúcares redutores nas estacas de kiwi 'Abbott' antes e após os tratamentos, nos 4 períodos estudados.

estacas coletadas durante o outono e inverno foram aquelas que mostraram o maior conteúdo de açúcares redutores.

ScL agric, Piracicaba, 52(3): 462-468, set/dez. 1995
A Figura 1 mostra que, nos 4 períodos estudados, os teores de açúcares redutores contidos nas estacas aumentaram com a aplicação dos tratamentos.

Os resultados sugerem que pode existir uma relação entre a quantidade de açúcares redutores e a porcentagem de enraizamento, pois as maiores médias de porcentagem de enraizamento foram obtidas no outono e inverno, sendo que a maior quantidade de açúcares também foram encontradas nessas mesmas Epocas.

Teor de açúcares totais: A Figura 2 mostra os resultados obtidos para teor de açúcares totais, antes e após os tratamentos, nas estacas de kiwi 'Abbott'. Pode-se notar que os teores de açúcares totais aumentaram durante o processo da formação de raízes, nas estacas de ramos colhidos no outono e inverno, sendo que estacas de ramos coletados na primavera e verão, mostraram redução nesses teores.

Anteriormente aos tratamentos, estacas de ramos coletados na primavera e verão, apresentaram maior conteúdo de açúcares totais.

As estacas de ramos coletados no outono e

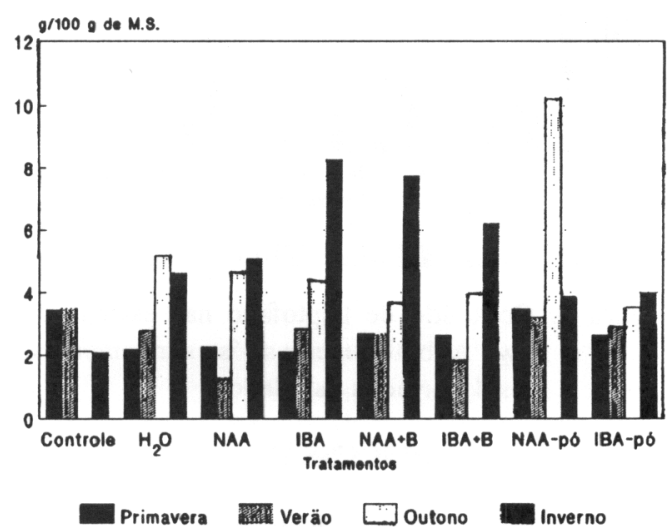

Figura 2. Conteúdo de açúcares totais nas estacas de kiwi 'Abbott' antes e apos os tratamentos, nos 4 períodos estudados.

tratadas com NAA 0,5\% (T6), apresentaram altos valores de açúcares totais. $O$ teor de açúcares totais das estacas de verão, não diferiram entre os 7 tratamentos realizados nas estacas. Estacas de ramos coletados no inverno, apresentaram o maior conteúdo de açúcares totais nas estacas tratadas com IBA 300 ppm (T3) e NAA 300 ppm + B (T4).

Numa análise geral, pode-se verificar que os maiores valores de açúcares totais foram 
encontrados nas estacas de outono, tratadas com NAA 0,5\% (T6) e nas estacas de inverno tratadas com com IBA 300 ppm (T3) e NAA 300 ppm + B (T4).

Teor de triptofano: Os resultados obtidos para teor de triptofano nas estacas de kiwi 'Abbott', está apresentado na Figura 3, pela qual pode-se observar que antes dos tratamentos não houve diferença nos teores de triptofano, nas diferentes épocas de coleta dos ramos. No entanto, essa mesma Figura evidencia que ocorreu diminuição no teor de triptofano no decorrer do período de enraizamento, em todas as épocas estudadas.

O maior conteúdo de triptofano após os tratamentos foi encontrado nas estacas de ramos coletados no verão, tratadas com IBA 0,5\% (T7).

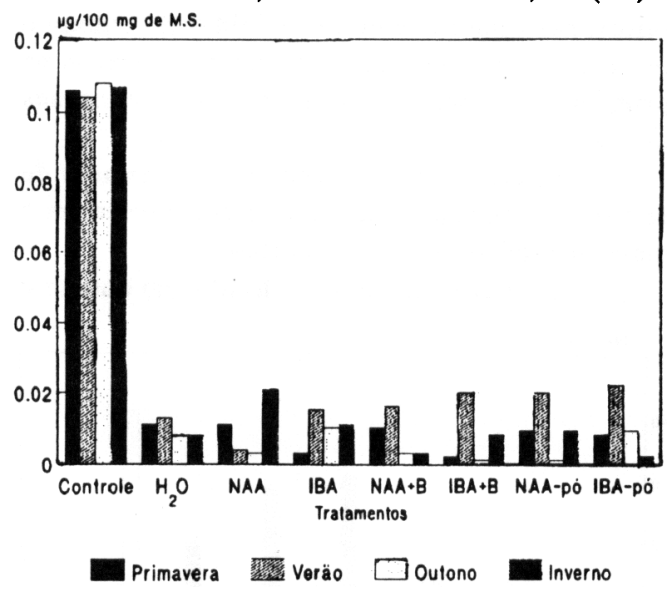

Figura 3. Conteúdo de triptofano nas estacas de kiwi 'Abbott' antes e após os tratamentos, nos 4 períodos estudados.

\section{DISCUSSÃO}

A partir desses resultados, pode-se observar que, no geral, para atingir maior porcentagem de enraizamento, estacas de ramos coletados no outono e inverno apresentam melhores resultados, sendo o tratamento T6 (NAA 0,5\%) o mais promissor nestas estações. Além disso, o NAA nas condições deste experimento, parece ter sido mais promissor que o IBA. De uma maneira geral, a adição de boro beneficiou no aumento da porcentagem de enraizamento, principalmente, quando adicionado juntamente com o NAA. DIRR \& FRETT (1983), trabalhando com estacas de Capressocyparis leydandii tratadas apenas com boro, não mostraram alta porcentagem de enraizamento, mas quando tratadas com IBA mais boro apresentaram sucesso no enraizamento. ONO et al. (1992), trabalhando com estacas de camélia (Camellia japonica L.), constaram que o enraizamento foi beneficiado pela adição de boro às auxinas.

Existe muita contradição, quanto à época de coleta dos ramos de kiwi que serão utilizados na confecção das estacas. Por exemplo, LAWES e SIM (1980), obtiveram rápida formação de raízes, em estacas coletadas no verão, fato mais tarde confirmado por POVES (1982). Já COSTA e BARALDI (1983) e VITAGLIANO et al. (1983), observaram baixa porcentagem de enraizamento em estacas coletadas no verão. Além disso, MORINI e ISOLERI (1986), relatam que existem dois períodos ótimos de coleta dos ramos, um no início da primavera e o outro no verão.

MORINI e ISOLERI (1986), trabalhando com estacas lenhosas de kiwi do cultivar Hayward, obtiveram 71,2\% de enraizamento naquelas tratadas com NAA à 5.000 ppm após 60 dias do plantio. Além disso, os mesmos autores, compararam 0 efeito do IBA e NAA sobre a formação de raízes, concluindo que o NAA foi mais efetivo, principalmente na concentração de $5.000 \mathrm{ppm}$, resultados semelhantes aos encontrados no presente trabalho.

LEE et al. (1978), trabalhando com estacas de hipocótilo de Phaseolus aureus, compararam o efeito do tratamento com IBA, NAA, IAA e 2,4-D, onde verificaram ser o NAA a auxina sintética mais efetiva no processo de enraizamento, seguido do IBA, 2,4-D e IAA. HINSELEY \& BLAZICH (1981), em estacas de Abies fraseri verificaram que IBA à $5.000 \mathrm{ppm}$ foi mais efetivo que o NAA na mesma concentração. Portanto, pode-se concluir que a efetividade do IBA e NAA, é dependente da espécie vegetal empregada, da forma de aplicação, e outros fatores.

Quanto ao conteúdo de açúcares redutores e totais, estes carboidratos, aparentemente, influenciaram na melhora da porcentagem de enraizamento. $O$ teor de açúcares redutores $\mathrm{e}$ açúcares totais, aumentou durante o processo de enraizamento, provavelmente devido à transformação de outros carboidratos em açúcares, bem como, devido à translocação desses açúcares das folhas para a estaca.

Além disso, essas observações indicam que os tratamentos com auxinas levaram ao aumento 
de açúcares redutores nas estacas, possivelmente por transporte das folhas ou por conversão.

Trabalhos têm mostrado a existência de interação entre os reguladores de crescimento e carboidratos solúveis. Já MITCHELL et al. (1940), relataram que o IAA e NAA aceleram a oxidação do amido.

Durante o desenvolvimento do primórdio radicular, o conteúdo de açúcares livres na base das estacas, muitas vezes aumenta devido à hidrólise do amido, ou devido ao aumento do transporte basípeto de açúcares, ou ambos (HAISSIG, 1974; ALTMAN e WAREING, 1975). A auxina endógena ou aplicada exógenamente, aumenta a hidrólise do amido (HAISSIG, 1974; DAVIS e POTTER, 1981). ALTMAN e WAREING (1975), sugerem que o IAA promove o enraizamento das estacas, por aumentar a disponibilidade de açúcares no sítio de desenvolvimento do primórdio radicular.

Pode-se sugerir que exista uma relação entre a quantidade de açúcares redutores e totais e a porcentagem de enraizamento, pois as épocas que levaram à elevada porcentagem de enraizamento foram o outono $e$ inverno, coincidindo com as épocas de maiores conteúdos de açúcares redutores e totais, encontrados nas estacas.

HAISSIG (1982), trabalhando com estacas de Phaseolus vulgaris L., concluíram que IAA aplicado exógenamente, facilita o transporte de açúcares redutores para a base das estacas, aumentando o enraizamento. Já FACHINELLO et al. (1988), em trabalho realizado com estacas de ramos de porta-enxerto de macieira (Mallus spp) 'MM106', concluíram que os aumentos nos teores de açúcares solúveis e de nitrogênio total na estaca, não foram acompanhados de aumentos no enraizamento.

As reservas orgânicas e, principalmente o amido, constituem um fator importante para o desenvolvimento de raízes adventícias (CHEFFINS e HOWARD, 1982), pois o amido quando presente na estaca constitui-se a única fonte de carboidratos que irá prover a energia necessária para a iniciação e o desenvolvimento de primórdios radiculares (VIEITZ et al., 1980).

O teor de triptofano encontrado nas estacas de kiwi, diminuiu significativamente, durante o processo de enraizamento, sendo alto antes dos tratamentos e, bastante reduzido após os tratamentos. Este fato, leva a concluir que o triptofano foi utilizado na formação do IAA, durante o processo de enraizamento. GORDON e PALEG
(1961) e SINGH (1981), afirmam ser o triptofano o precursor na formação do IAA.

No entanto, não houve relaçãao entre o conteúdo de triptofano e a porcentagem de enraizamento, pois os teores de triptofano anteriormente aos tratamentos, foram semelhantes nas 4 épocas estudadas.

\section{CONCLUSÃo}

Através dos resultados obtidos no processo de enraizamento de estacas caulinares de kiwi (Actinidia chinensis Planch. cv Abbott), pode-se observar as seguintes conclusões:

- outono e inverno foram as melhores épocas de coleta dos ramos, para a confecção das estacas; - o tratamento das estacas com NAA à $0,5 \%$ na forma de talco, beneficia o processo de enraizamento;

- parece existir relação entre o conteúdo de açúcares redutores e totais, sendo que estacas que apresentaram maior conteúdo desses açúcares, apresentaram maior porcentagem de enraizamento.

\section{REFERÊNCIAS BIBLIOGRÁFICAS}

ALTMAN, A., WAREING, P.F. The effect of IAA on sugar accumulation and basipetal transport of ${ }^{14} \mathrm{C}$ labelled assimilates in relation to root formation in Phaseolus vulgaris cuttings. Physiol. Plant., Copenhagen, v.33, p.32-38, 1975.

BOSMAN, D.C., UYS, D.C. Propagation of kiwifruit from softwood cuttings. Decidous Fruit Grower, Cape Town, v.28,n.9, p.334-336, 1978.

CHEFFINS, N.J., HOWARD, B.H. Carbohydrate changes in leaflese winter apple cuttings. I. The influence of level and duration of bottom heat. $J$. Hortic. Sci., London, v.57, n.1, p.1-9, 1982.

COSTA, G., BARALDI, R. Ricerche sulla propagazione per talea legnosa dell Actinidia chinensis. Riv. Ortoflorofruticolt. Ital., Florence, v.67, p. 123-128, 1983.

DAVIS, T.D., POTTER, J.R. Current photosynthate as a limiting factor in adventitious root formation on leafy pea cuttings. J. Amer. Soc. Hortic. Sci., Alexandria, v.106, p.278-282, 1981 .

DIRR, M.A., FRETT, J.J. Rooting Leyland cypress as affected by indolebutyric acid and boron treatment. Hortscience, Alexandria, v.18, p.204-205, 1983. 
DONONAN, D.M. A list of plants regenerating from root cuttings. Planch. Prop., London, v.22, p.7-8, 1976.

DUTTA, T.R., Mc ILRATH, W.J. Effects of boron on growth and lignification in sunflower tissue. Bot. Gaz., Chicago, v.125, p.89, 1964.

FACHINELLO, J.C., LUCCHESI, A.A., GUTIERREZ, L.E. Influência do anelamento de estacas lenhosas do porta-enxerto 'Malling-Merton 106'. Pesq. agropec. bras., Brasilia, v.23, n.9, p.1025-1031, 1988.

GORDON, S.A., PALEG, L.G. Formation of auxin from tryptophan through actio of polyphenols. Plant Physiol., Bethesda, v.36, p.838-845, 1961.

HAISSIG, B.E. Influences as of auxins and auxin synergists on adventitious root primondium initiation and development. N. Z. J. For. Sci., v.4, p.311323, 1974 .

HAISSIG, B.E. Activity of some glycolitic and pentose phosphate pathway enzymes during the development of adventitious roots. Phsyiol. Plant., Copenhagen, v.55, p.261-272, 1982.

HARTMANN, H.T., KESTER, D.E., DAVIES Jr., F.T. Plant propagation; principles and practices. 5.ed. New York: Englewood Clipps/ Prentice-Hall, 1990. 647p.

HEMBERG, T. Growth inhibiting substances in terminal buds of Fraxinus. Physiol. Plant., Copenhagen, v.2, p.37-44, 1949.

HINSELEY, L.E., BLAZICH, F.A. Influence of severance treatments on the rooting capacity of Fraserfir stem cuttings. Can. J. For. Res., v.11, p.316$323,1981$.

JARVIS, B.C., ALI, A.H.N., SHAHEED, A.I. Auxin and boron in relation to the response and ageing of mung bean cuttings. New Phytol., Cambridge, v.95, p.509-518, 1983.

KERSTEN, E. Efeito do boro, zinco e ácido indolbutf́rico no enraizamento de estacas de dois cultivares de ameixeira (Prunus salicina Lindl.). Piracicaba: USP, 1990. 109p. Tese (Doutorado em Agronomia) - Escola Superior de Agricultura "Luiz de Queiroz", USP, 1990.

LAWES, G.S., SM, B.L. An analysis of factors affecting the propagation of kiwifruit. Orchardist New Zealand, New Zealand, v.53, n.3, p.88-90, 1980.

LEE, L.S., CHEN, Y.M., LIN, C.Y. Studies on the formation of adventitious root initial in mung bean hypocotyl. Taiwania, Taipei, v.23, p.155-122, 1978.

LEWIS, D.H. Boron, lignification and the origin of vascular plants - a unified hypothesis. New Phytol., Cambridge, v.84, p.209-229, 1980.
MIDDLETON, W., JARVIS, B.C., BOOTH, A. The boron requirement for root development in stem cutting of Phaseolus aureus Roxb. New Phytol., Cambridge, v.81, p.287, 1978.

MITCHELL, J.W., KRAUS, E.J., WHITEHEAD, M.R. Starch hydrolisis in bean leaves following spraying with alpha naphthalene acetic acid emulsion. Bot. Gaz., Chicago, v.102, p.97-104, 1940.

MORINI, S., ISOLERI, M. Effect of IBA and NAA on rooting of Actinidla chinensis cuttings. Acta Hortic., Wageningen, n.179, p.885-886, 1986.

NELSON, N. A photometric adaptation of the Somogy method for determination of glucose. J. Biol. Chem., v.153, p.375-380, 1944.

ODHNOFF, C. Boron deficiency and growth. Physiol. Plant., Copenhagen, v.10, p.984-1000, 1957.

ONO, E.O., RODRIGUES, J.D., RODRIGUES, S.D. Interaçōes entre auxinas e boro no enraizamento de estacas de camélia. R. Bras. Fisiol. Vego, São Carlos, v.4, n.2, p.107-112, 1992.

PIMENTEL GOMES, F. Curso de estatística experimental. 13.ed. Piracicaba: Nobel, 1990. 468p.

POVES, L.T. D liwi o Actinidia. 1.ed. Madrid: Hojas Divulgadoras del Ministerio de Agricultura, Pesca y Alimentacion, 1982. 24p.

SINGH, M. Effect of zinc, phosphorus ad nitrogen on tryptophan concentration in rice grains grown on limed and unlimed soils. Plant Soil, Dordrecht, v.62, n.2, p.305-308, 1981.

STOUTEMYER, V.T. Root cuttings. P1.Prop., London, v.14, p.4-7, 1968 .

VIEITZ, A.M., BALLESTER, A., GARCIA, M.T., VIEITZ, E. Starch depletion and anatomical changes during the rooting of Castanea sativa Mill, cuttings. Scientia Horticulturae, Canterbury, v.13, p.261-266, 1980.

VITAGLIANO, C., TESTOLINI,R, YOUSSEF, J. Osservazioni su alcuni fattori influenzanti la rizogenesi di talee legnose e semi-legnose di Actinidia (Actinidia chinensis Planch.). In: INCONTRO FRUTTICOLO SULL ACTINIDIA, 2, 1983, Atti , 1983, p.611637.

WEAVER, R.J. Reguladores del crecimiento en la Agricultura. Barcelona: Trillas, 1982. 540p.

WEISER, C.J. Effect of boron on the rooting of Clematis cuttings. Nature, London, v.183, p.559, 1959.

ZUCCHERELLI, G., ZUCCHERELLI, G. La Actinidia planta da frutto e da giardino. Bologna: Edagricole, 1980. 198p.

Recebido para publicação em 09.01 .95

Aceito para publicação em 02.05 .95 